\title{
Genetic differentiation and local temporal stability of population structure in the euphausiid Meganyctiphanes norvegica
}

\author{
Chiara Papetti ${ }^{1}$, Lorenzo Zane $^{1}$, Erica Bortolotto ${ }^{1}$, Ann Bucklin ${ }^{3}$, Tomaso Patarnello ${ }^{1,2, *}$ \\ ${ }^{1}$ Department of Biology, University of Padova, via U. Bassi 58/B, 35121 Padova, Italy \\ ${ }^{2}$ Faculty of Veterinary Medicine, University of Padova, Agripolis, via Romea 16, 35020 Legnaro (Pd), Italy \\ ${ }^{3}$ Ocean Process Analysis Laboratory, University of New Hampshire, Durham, New Hampshire 03824, USA
}

\begin{abstract}
Meganyctiphanes norvegica (M. Sars 1856), the northern krill, is the largest and most abundant euphausiid species in the northern hemisphere, where it represents a key component of many pelagic communities. Although planktonic, krill could be considered a nektonic organism, as it is capable of active movements. This behaviour may be adaptive, because it allows these organisms to maintain their geographic position, leading to stable population structure, despite being continuously exposed to the heterogeneous oceanic conditions. By means of single-strand conformation polymorphism and DNA sequencing, we analyzed allelic variation of the Subunit 1 of NADH dehydrogenase mtDNA locus in 23 populations of the northern krill Meganyctiphanes norvegica, from 15 locations spanning the distribution range of the species. Analysis of the data indicated that the genetic structure, as revealed by analysis of population samples collected at the same site in consecutive years, was stable during that sampling period. Our results revealed the existence of 4 genetically and geographically distinct gene pools of M. norvegica, 2 occurring in the NE Atlantic ('northern' NE Atlantic and 'southern' NE Atlantic), 1 in the NW Atlantic, and 1 in the Mediterranean (Ligurian) Sea.
\end{abstract}

KEY WORDS: Meganyctiphanes norvegica $\cdot$ Northern krill $\cdot$ Population genetics $\cdot$ mtDNA $\cdot$ NADH dehydrogenase $\cdot$ SSCP $\cdot$ Gene pool

\section{INTRODUCTION}

Meganyctiphanes norvegica (M. Sars 1856), the northern krill, is the largest and probably the most abundant euphausiid species in the northern hemisphere, where it represents a key component of many pelagic communities. $M$. norvegica has a wide distribution in the North Atlantic between 30 and $80^{\circ} \mathrm{N}$; from Canada to the Arctic to the western Mediterranean. The distribution encompasses water masses and oceanographic conditions as varied as open oceans, marginal seas and fjords. The species seems constrained to water temperatures which range between 2 and $15^{\circ} \mathrm{C}$ (Lindley 1982), but there are exceptions, generally for trophic reasons (Siegel 2000). For instance, when nutrition is a limiting factor (Saborowski et al. 2002), krill are apparently able to choose highly productive water masses with sub-optimal temperature conditions (Taki et al. 1993). Thus, although considered planktonic, krill are at the boundary with nektonic organisms, those capable of active movements.

Krill of all sizes can potentially be carried away by ocean currents, but only larval and juvenile organisms can be easily transported. Older and larger individuals can achieve swimming speeds similar to average current speeds (see e.g. Kils 1982 for Euphausia superba). Thus, Meganyctiphanes norvegica has a certain capacity to determine its distribution on small horizontal (geographic) scales or vertically in the water col- 
umn. In fact, $M$. norvegica is a strong vertical migrator and shows a consistent pattern of segregation during upward vertical movement at night time (Tarling et al. 1999). Night time segregation does not appear to be a passive process (Worthington 1931, Hardy \& Gunther 1935, Mauchline 1980, Kils 1982), but rather an active behaviour resulting from differential swimming or sinking rates (which vary according to the size) in response to both internal physiological processes and also external stimuli (i.e. escaping from predators, foraging). Downward movements have often been considered as passive behaviour, where the animal stops swimming and sinks. Acoustic Doppler current profiles have suggested the opposite: that $M$. norvegica, below $200 \mathrm{~m}$ of depth, increases its downward velocity with active movements (Tarling et al. 2001).

The active movements of adult Meganyctiphanes norvegica may represent an adaptive behaviour, as they allow the species to maintain a stable population structure, while continuously being exposed to heterogeneous oceanic conditions (Buchholz et al. 1998). This aspect has to be taken into account when dealing with dispersal and gene flow of the northern krill, because active swimming could have an effect on the stability of the population's genetic structure at particular geographic locations, especially where self-sustaining populations of M. norvegica are known to occur (Mauchline \& Fisher 1969). While adults are capable of retaining location, larvae are dispersive agents. The fact that larvae are released from restricted geographic locations (i.e. the discrete regions occupied by adult populations) implies, however, that there are limits to the maximum geographic range of dispersion.

In the NW Atlantic, Meganyctiphanes norvegica is known to reproduce in the Gulf of St. Lawrence, in the Gulf of Maine and on the Scotian Shelf, although Herman et al. (1991) concluded that Scotian Shelf plankton biomass production is enriched by transport from the St. Lawrence Gulf (see Bucklin et al. 1997) (Fig. 1). In contrast, in the Ligurian Sea, krill are consistently associated with a stable oceanographic front occurring off Nice (Cuzin-Roudy 2000). In this area, $M$. norvegica plays an important trophic role as the main food source for the fin whale Balaenoptera physalus (Boucher \& Thiriot 1972), which exploits the night time upward migration of krill (Forcada et al. 1993). Interestingly, this fin whale population seems to be stably resident in the Ligurian Sea and was shown to be genetically isolated (Bérubé et al. 1998). At least 2 other self-maintaining krill populations are well documented in the Baltic Sea: one in the Skagerrak Sea, which indirectly sustains the active cod and anchovy fishery, and a second in the Kattegat Sea, which is specifically associated with the Læsø Deep depression, where Baltic and Skagerrak waters mix together (Buchholz \& Boysen-Ennen 1988, Fig. 1). Despite the strong Atlantic currents, M. norvegica also likely consists of a self-sustaining population in the Clyde Sea and in the Cadiz Bay, where southern currents may play a role in the transport of individuals from the Morocco coast (Mauchline 1980, Zane et al. 2000).

Genetic investigations at the intra-specific level need to employ fast-evolving genes suitable to detect the sometimes subtle differences between populations. Mitochondrial DNA (mtDNA) is maternally inherited and has a faster mutation rate than the nuclear genome. For this reason it has been used for studying the population structure of many marine organisms including Meganyctiphanes norvegica. In this species cytochrome oxidase Subunit I (COI) and NADH dehydrogenase Subunit 1 (ND1) mitochondrial genes were successfully used as molecular markers (reviewed in Zane \& Patarnello 2000).

This study builds upon 2 previous population genetic studies of this species by Bucklin et al. (1997) and Zane et al. (2000). In the first study, mtDNA sequence variation revealed significant structuring of populations at trans-ocean basin scales. Bucklin et al. (1997) concluded that (1) genetic heterogeneity among samples reflected high levels of molecular genetic diversity, and perhaps, under-sampling of the population genetic

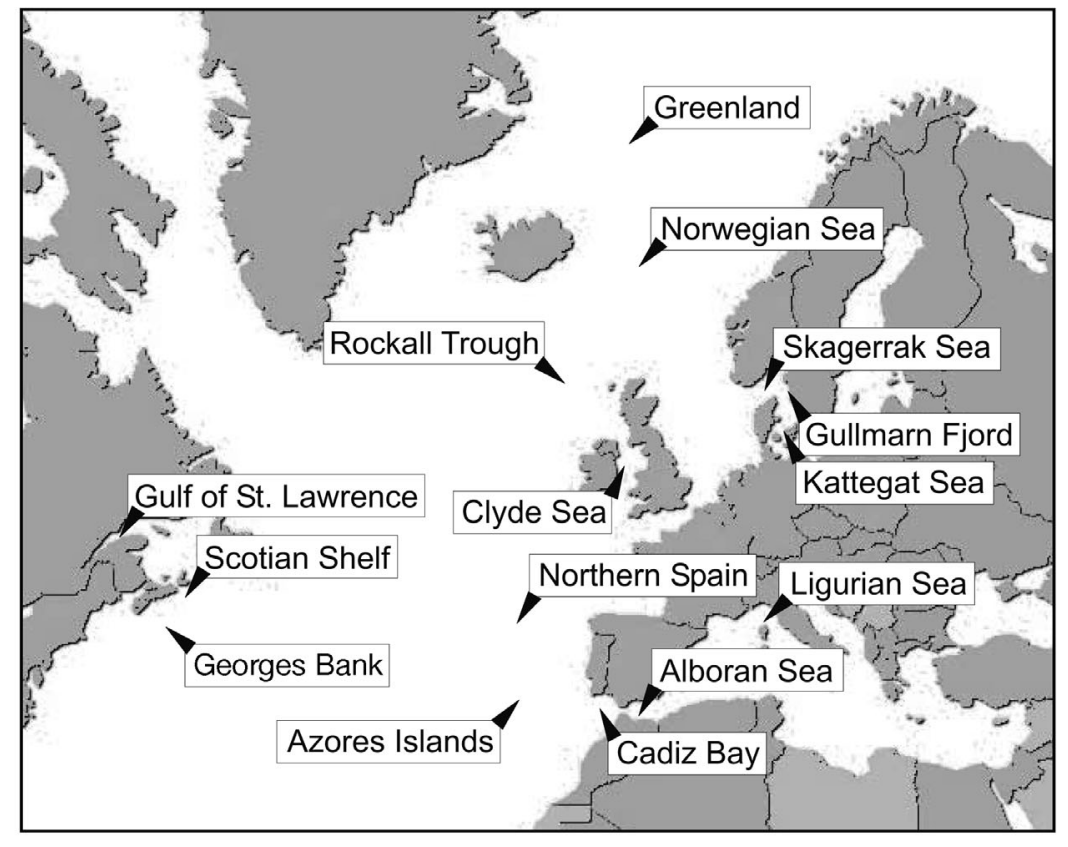

Fig. 1. Meganyctiphanes norvegica sampling sites 
structure; (2) gene flow of Meganyctiphanes norvegica within the NW Atlantic was sufficient to prevent the formation of distinctive geographic populations, except in the case of the Gulf of St. Lawrence sample collected in 1994; and (3) genetic differentiation of the NW Atlantic and Norwegian fjord populations indicated highly restricted gene flow across the North Atlantic Ocean. Zane et al. (2000) also found significant genetic differentiation among populations investigated across the NE Atlantic and the Mediterranean Sea, and concluded that (1) a large portion of the total genetic variability was explained by differences between populations, indicating absence of panmixia for these populations; and (2) pairwise comparisons revealed 3 distinct gene pools, one represented by the Cadiz Bay population, the second by the Ligurian Sea population, and the third by the NE Atlantic samples.

The present work was aimed at building upon the findings of these previous papers and providing more detailed information on the genetic structure of the northern krill. In particular, this paper improves upon these earlier efforts by increasing the geographic focus to include a large portion of the species' natural range, and by increasing the spatial resolution of sampling. Our goal is to (1) extend our knowledge on the population structure of this species at a large geographic scale; and (2) test temporal stability of the previously reported population subdivision.

\section{MATERIALS AND METHODS}

Sampling and DNA extraction. A total of 982 individuals (23 population samples) of Meganyctiphanes norvegica were collected from different sites as shown in Table 1 and in Fig. 1. A large part of these samples were collected as part of the EU funded research project 'PEP' (Impact of a Climatic Gradient on the Physiological Ecology of Pelagic Crustacean, www.obsvlfr.fr/PEP/.index.html) between 1995 and 1998. Krill were individually stored in vials containing $70 \%$ ethanol. DNA for PCR amplification was released using a Chelex protocol (Walsh et al. 1991) from a few $\mathrm{mg}$ of specimen.

DNA amplification, SSCP analysis and sequencing. A $155 \mathrm{bp}$ fragment of the Subunit 1 of the ND1 mitochondrial gene was amplified in all specimens using the primers ND1af and ND1ar (Zane et al. 2000). Single-strand conformation polymorphism (SSCP) was assayed for all individuals as described in Ostellari et al. (1996) and Zane et al. (2000). The SSCP protocol detects differences in DNA sequences. Due to their sequence, DNA fragments migrate through the polyacrilamide gel with a different mobility pattern, and each mobility variant can be associated with a specific haplotype. For sequencing purposes, a larger fragment was amplified using the primers ND1f and ND1ar (Zane et al. 1998). The fragment was purified using a

Table 1. Geographic sector, sites of collection, synthetic code, geographic coordinates, sample size (n) and date of collection of Meganyctiphanes norvegica samples

\begin{tabular}{|c|c|c|c|c|c|c|}
\hline $\begin{array}{l}\text { Geographic } \\
\text { sector }\end{array}$ & $\begin{array}{l}\text { Collection } \\
\text { site }\end{array}$ & $\begin{array}{l}\text { Synthetic } \\
\text { code }\end{array}$ & $\begin{array}{l}\text { Latitude and } \\
\text { longitude }\end{array}$ & $\mathrm{n}$ & $\begin{array}{l}\text { Collection } \\
\text { date }(\mathrm{d} / \mathrm{mo} / \mathrm{yr})\end{array}$ & Source \\
\hline 'Southern' & Azores Islands & Azores & $38^{\circ} 30^{\prime} 00^{\prime \prime} \mathrm{N}-28^{\circ} 38^{\prime} 00^{\prime \prime} \mathrm{W}$ & 51 & $25 / 05 / 2003$ & This work \\
\hline NE Atlantic & Cadiz Bay & Cadiz & $36^{\circ} 15^{\prime} 39^{\prime \prime} \mathrm{N}-6^{\circ} 48^{\prime} 39^{\prime \prime} \mathrm{W}$ & 47 & 29/09/1997 & Zane et al. (2000) \\
\hline Ocean & NW Spain & NW Spain & $42^{\circ} 22^{\prime} 00^{\prime \prime} \mathrm{N}-16^{\circ} 37^{\prime} 00^{\prime \prime} \mathrm{W}$ & 48 & $16 / 08 / 2000$ & This work \\
\hline Mediterranean & Alboran Sea & Alboran & $36^{\circ} 27^{\prime} 76^{\prime \prime} \mathrm{N}-1^{\circ} 34^{\prime} 84^{\prime \prime} \mathrm{E}$ & 46 & 14/01/1997 & Zane et al. (2000) \\
\hline \multirow[t]{2}{*}{ Sea } & Ligurian Sea & Lig1996 & $43^{\circ} 39^{\prime} 00^{\prime \prime} \mathrm{N}-7^{\circ} 22^{\prime} 00^{\prime \prime} \mathrm{E}$ & 50 & 24/04/1996 & Zane et al. $(2000)$ \\
\hline & Ligurian Sea & Lig1997 & $43^{\circ} 16^{\prime} 03^{\prime \prime} \mathrm{N}-7^{\circ} 55^{\prime} 02^{\prime \prime} \mathrm{E}$ & 52 & 10/09/1997 & This work \\
\hline 'Northern' & Clyde Sea & Cly1996 & $55^{\circ} 42^{\prime} 70^{\prime \prime} \mathrm{N}-5^{\circ} 10^{\prime} 00^{\prime \prime} \mathrm{W}$ & 46 & 05/07/1996 & Zane et al. (2000) \\
\hline NE Atlantic & Clyde Sea & Cly1997 & $55^{\circ} 18^{\prime} 00^{\prime \prime} \mathrm{N}-5^{\circ} 04^{\prime} 00^{\prime \prime} \mathrm{W}$ & 57 & 26/02/1997 & This work \\
\hline \multirow[t]{11}{*}{ Ocean } & Greenland & Greenland & $74^{\circ} 24^{\prime} 05^{\prime \prime} \mathrm{N}-10^{\circ} 19^{\prime} 04^{\prime \prime} \mathrm{W}$ & 49 & 06/10/1999 & This work \\
\hline & Gullmarn Fijord & Gullmarn & $58^{\circ} 20^{\prime} 16^{\prime \prime} \mathrm{N}-11^{\circ} 39^{\prime} 64^{\prime \prime} \mathrm{E}$ & 48 & 28/07/1998 & This work \\
\hline & Kattegat Sea & Kat1995 & $57^{\circ} 16^{\prime} 60^{\prime \prime} \mathrm{N}-11^{\circ} 25^{\prime} 00^{\prime \prime} \mathrm{E}$ & 50 & 01/08/1995 & Zane et al. (2000) \\
\hline & Kattegat Sea & Kat1996 & $57^{\circ} 16^{\prime} 60^{\prime \prime} \mathrm{N}-11^{\circ} 25^{\prime} 00^{\prime \prime} \mathrm{E}$ & 49 & 13/07/1996 & Zane et al. (2000) \\
\hline & Kattegat Sea & Kat1997 & $57^{\circ} 16^{\prime} 50^{\prime \prime} \mathrm{N}-11^{\circ} 25^{\prime} 01^{\prime \prime} \mathrm{E}$ & 57 & 07/03/1997 & This work \\
\hline & Kattegat Sea & Kat1998 & $57^{\circ} 17^{\prime} 06^{\prime \prime} \mathrm{N}-9^{\circ} 47^{\prime} 00^{\prime \prime} \mathrm{E}$ & 49 & $31 / 07 / 1998$ & This work \\
\hline & Norwegian Sea & Atl1997 & $60^{\circ} 54^{\prime} 10^{\prime \prime} \mathrm{N}-4^{\circ} 30^{\prime} 72^{\prime \prime} \mathrm{W}$ & 55 & 15/03/1997 & This work \\
\hline & Rockall Trough & Atl1996 & $57^{\circ} 22^{\prime} 00^{\prime \prime} \mathrm{N}-10^{\circ} 20^{\prime} 00^{\prime \prime} \mathrm{W}$ & 50 & 23/06/1996 & Zane et al. (2000) \\
\hline & Skagerrak Sea & Ska1996 & $58^{\circ} 15^{\prime} 00^{\prime \prime} \mathrm{N}-10^{\circ} 25^{\prime} 00^{\prime \prime} \mathrm{E}$ & 47 & 16/07/1996 & Zane et al. (2000) \\
\hline & Skagerrak Sea & Ska1997 & $58^{\circ} 01^{\prime} 02^{\prime \prime} \mathrm{N}-9^{\circ} 43^{\prime} 00^{\prime \prime} \mathrm{E}$ & 54 & 04/03/1997 & This work \\
\hline & Skagerrak Sea & Ska1998 & $58^{\circ} 00^{\prime} 00^{\prime \prime} \mathrm{N}-9^{\circ} 47^{\prime} 00^{\prime \prime} \mathrm{E}$ & 43 & $21 / 07 / 1998$ & This work \\
\hline NW Atlantic & Georges Bank & G. Bank & $41^{\circ} 21^{\prime} 00^{\prime \prime} \mathrm{N}-69^{\circ} 05^{\prime} 40^{\prime \prime} \mathrm{W}$ & 9 & 09/06/1994 & This work \\
\hline \multirow[t]{3}{*}{ Ocean } & Gulf St. Lawrence & Stlaw93 & $48^{\circ} 40^{\prime} 00^{\prime \prime} \mathrm{N}-68^{\circ} 35^{\prime} 00^{\prime \prime} \mathrm{W}$ & 6 & 02/06/1993 & This work \\
\hline & Gulf St. Lawrence & Stlaw94 & $48^{\circ} 36^{\prime} 29^{\prime \prime} \mathrm{N}-68^{\circ} 37^{\prime} 60^{\prime \prime} \mathrm{W}$ & 7 & 01/09/1994 & This work \\
\hline & Scotian Shelf & Scotian S. & $42^{\circ} 48^{\prime} 00^{\prime \prime} \mathrm{N}-62^{\circ} 28^{\prime} 00^{\prime \prime} \mathrm{W}$ & 12 & 07/06/1994 & This work \\
\hline
\end{tabular}


commercial kit (QIAquick PCR, QIAGEN) and sequenced with the primer ND1f. The sequencing service was provided by C.R.I.B.I. (Centro Interdipartimentale per le Biotecnologie Innovative) (Department of Biology, University of Padova, for more information see http://bmr.cribi.unipd.it/).

Correspondence between haplotype and mobility class as well as identification of rare or new haplotypes were checked through sequencing. In all cases, PCR fragments having the same electrophoretic mobility also showed the same sequence, confirming the $100 \%$ accuracy of the SSCP approach in discriminating haplotypes, at least for this PCR fragment and species.

Haplotype genealogy. The sequence information for ND1 was used to reconstruct genealogical relationships among haplotypes by a network, as implemented in the program T.C.S. 1.13 (T.C.S.: Phylogenetic network estimation using statistical parsimony), based on the parsimony method (Clement et al. 2000). The network makes it possible to maintain different alternative connections between haplotypes. However, according to coalescent theory (Hudson 1990), in a population at equilibrium, the ancestral and most frequent haplotypes generate the rarest. Consequently, we modified each network rejecting connections between rare haplotypes, considering them less probable (Bandelt et al. 1995) and for this reason not supported.

Population structure analysis. All population structure analyses were performed using Arlequin version 2.000 (Schneider et al. 2000). Haplotype diversity (h) and nucleotide diversity $(\pi)$ (Nei \& Miller 1990) were calculated for each population. Overall genetic heterogeneity was tested using an analysis of molecular variance (AMOVA) approach (Excoffier et al. 1992). This approach performs a standard analysis of variance, in which the total variance is partitioned in covariance components due to inter-individual differences, interpopulation differences, and differences between groups of populations. Covariance components are used to calculate fixation indices ( $F$ or $\Phi$, see below) among groups of populations (indicated by subscript $c t$ ), among populations within groups $(S C)$, or among populations (st). Because AMOVA computed on the variance of gene frequencies is equivalent to a conventional F-statistic analysis sensu Cockerham (1969, 1973), we will indicate the corresponding fixation indices as $F_{s t} F_{s C}$ and $F_{s t}$. Alternatively, AMOVA takes into account the number of mutations between haplotypes in the calculation of variance, in this case we will indicate fixation indices as $\Phi_{s t}, \Phi_{s c}$ and $\Phi_{c t}$.

Statistical significance was assessed by comparing the observed distribution with a 'random distribution' generated by a permutational approach (in this case with 10000 permutations) in which individuals were randomly reallocated to each population. The same ap- proach was applied to estimate the level of population genetic divergence, by calculating $\Phi_{s t}\left(\right.$ or $F_{s t}$ ) and the associated probability level for each pair of populations. Significance threshold values were adjusted with a sequential Bonferroni correction (Rice 1989) that corrects for sampling error associated with multiple tests in order to reduce the group-wide Type I error rate. The matrices of pairwise genetic distances (obtained from both the conventional $F_{s t}$ and the $\Phi_{s t}$ ) were used to generate an unweighted pair-group method with arithmetic averages (UPGMA) dendrogram, which describes the relationships among populations, considering the rate of differentiation to be constant during the evolutionary history of each population.

Divergence time. We calculated the divergence time $(\tau)$ between differentiated gene pools following the approach of Gaggiotti \& Excoffier (2000) implemented in Arlequin (Schneider et al. 2000). This model assumes that populations have diverged from an ancestral population $T$ generations in the past, and have remained isolated since then. The method estimates $\tau$ in generations, scaled by the mutation rate $(\mu)$, according to the formula $\tau=2 T \mu$.

\section{RESULTS}

The SSCP technique resolved 35 different mobility classes among 982 individuals of Meganyctiphanes norvegica (Table 2, GenBank accession numbers AF150612-AF150623 to AY850542-AY850564) corresponding to different haplotypes of a $155 \mathrm{bp}$ segment of the ND1 mitochondrial gene. Two haplotypes (A and B) were present at high frequencies in all populations (Table 2), representing 48 and $42 \%$ of the entire sample set, respectively. It is worth noting that, in the coalescent-based T.C.S. network (Fig. 2), under the hypothesis of a stable population, A and B appeared as the ancestral haplotypes from which all others stemmed. With the exception of L and C ( 3 and $2 \%$, respectively), most of the remaining haplotypes were not shared among all populations, they were scored only in 1 or few specimens, and each accounted for less than $1 \%$ of the total frequency. No evidence of haplotype geographic grouping was found, however populations showed clear differences in haplotypes frequencies. Overall haplotype diversity $(h=0.445 \pm 0.0609)$ and nucleotide diversity $(\pi=0.005 \pm 0.004)$ values were low to moderate; most of the 35 haplotypes differed by 1 or 2 mutations. Haplotype diversity, measured within populations ranged between $h=0.733$ (St. Lawrence sample collected in 1993) and $h=0.124$ (Cadiz Bay population, Table 2).

An AMOVA was first performed on temporal replicates from the same site, Clyde Sea (2 samples), Katte- 
Table 2. Meganyctiphanes norvegica. Haplotype frequency, haplotype diversity $(h)$ and nucleotide diversity $(\pi)$ observed in the investigated populations. Values are reported for each sample and for population pools (in bold). Rare haplotypes (D, E, F, G, H, I, J, K, M, N, O, P, Q, R, S, T, U, V, W, X, Y, Z, AA, BB, CC, DD, EE, FF, GG, HH, II) were pooled together

\begin{tabular}{|c|c|c|c|c|c|c|c|c|}
\hline \multirow{2}{*}{ Populations } & \multirow[t]{2}{*}{$\mathrm{n}$} & \multicolumn{5}{|c|}{ - Haplotypes } & \multirow{2}{*}{$\begin{array}{l}\text { Haplotype diversity } \\
\text { (h) }\end{array}$} & \multirow{2}{*}{$\begin{array}{c}\text { Nucleotide diversity } \\
(\pi)\end{array}$} \\
\hline & & $\mathrm{A}$ & B & $\mathrm{L}$ & $\mathrm{C}$ & Rare haplotypes & & \\
\hline Azores Islands & 51 & 5 & 43 & 0 & 2 & 1 & $0.2831 \pm 0.0787$ & $0.003977 \pm 0.003543$ \\
\hline Cadiz Bay & 47 & 2 & 44 & 0 & 0 & 1 & $0.1240 \pm 0.0643$ & $0.001062 \pm 0.001627$ \\
\hline NW Spain & 48 & 4 & 37 & 0 & 1 & 6 & $0.4016 \pm 0.0872$ & $0.005010 \pm 0.004130$ \\
\hline Alboran Sea & 46 & 32 & 13 & 0 & 0 & 1 & $0.4454 \pm 0.0609$ & $0.002955 \pm 0.002944$ \\
\hline Lig1996 & 50 & 41 & 6 & 0 & 2 & 1 & $0.3176 \pm 0.0797$ & $0.003671 \pm 0.003367$ \\
\hline Lig1997 & 52 & 40 & 7 & 0 & 2 & 3 & $0.3944 \pm 0.0797$ & $0.004851 \pm 0.004035$ \\
\hline Ligurian Sea & 102 & 81 & 13 & $\mathbf{0}$ & 4 & 4 & $0.3545 \pm 0.0567$ & $0.004248 \pm 0.003662$ \\
\hline Cly1996 & 46 & 24 & 15 & 4 & 1 & 2 & $0.6261 \pm 0.0504$ & $0.005978 \pm 0.004662$ \\
\hline Cly1997 & 57 & 28 & 18 & 3 & 3 & 5 & $0.6635 \pm 0.0464$ & $0.007519 \pm 0.005456$ \\
\hline Clyde Sea & 103 & 52 & 33 & 7 & 4 & 7 & $0.6419 \pm 0.0342$ & $0.006781 \pm 0.005029$ \\
\hline Greenland & 49 & 23 & 24 & 0 & 0 & 2 & $0.5502 \pm 0.0297$ & $0.003818 \pm 0.003454$ \\
\hline Gullmarn Fijord & 48 & 21 & 21 & 0 & 1 & 5 & $0.6268 \pm 0.0413$ & $0.005685 \pm 0.004499$ \\
\hline Kat1995 & 50 & 23 & 20 & 7 & 0 & 0 & $0.6212 \pm 0.0326$ & $0.004745 \pm 0.003979$ \\
\hline Kat1996 & 49 & 26 & 20 & 3 & 0 & 0 & $0.5595 \pm 0.0358$ & $0.003939 \pm 0.003524$ \\
\hline Kat1997 & 57 & 31 & 21 & 1 & 0 & 4 & $0.5771 \pm 0.0420$ & $0.004689 \pm 0.003938$ \\
\hline Kat1998 & 49 & 27 & 16 & 1 & 2 & 3 & $0.5986 \pm 0.0519$ & $0.006528 \pm 0.004950$ \\
\hline Kattegat Sea & 205 & 107 & 77 & 12 & 2 & 7 & $0.5857 \pm 0.0206$ & $0.004942 \pm 0.004027$ \\
\hline Norwegian Sea & 55 & 31 & 19 & 1 & 1 & 3 & $0.5710 \pm 0.0460$ & $0.004822 \pm 0.004015$ \\
\hline Rockall Trough & 50 & 27 & 22 & 0 & 0 & 1 & $0.5249 \pm 0.0272$ & $0.003760 \pm 0.003419$ \\
\hline Ska1996 & 47 & 23 & 20 & 2 & 0 & 2 & $0.5893 \pm 0.0386$ & $0.004560 \pm 0.003881$ \\
\hline Ska1997 & 54 & 28 & 21 & 1 & 1 & 3 & $0.5884 \pm 0.0401$ & $0.005090 \pm 0.004164$ \\
\hline Ska1998 & 43 & 20 & 17 & 1 & 2 & 3 & $0.6379 \pm 0.0460$ & $0.006702 \pm 0.005057$ \\
\hline Skagerrak Sea & 144 & 71 & 58 & 4 & 3 & 8 & $0.5969 \pm 0.0236$ & $0.005350 \pm 0.004256$ \\
\hline George Bank & 9 & 5 & 3 & 0 & 1 & 0 & $0.6389 \pm 0.1258$ & $0.008961 \pm 0.006865$ \\
\hline Stlaw93 & 6 & 3 & 1 & 2 & 0 & 0 & $0.7333 \pm 0.1552$ & $0.005591 \pm 0.005221$ \\
\hline Stlaw94 & 7 & 6 & 1 & 0 & 0 & 0 & $0.2857 \pm 0.1964$ & $0.001843 \pm 0.002519$ \\
\hline Scotian Shelf & 12 & 7 & 2 & 2 & 0 & 1 & $0.6515 \pm 0.1327$ & $0.004985 \pm 0.004396$ \\
\hline NW Atlantic Ocean & 34 & 21 & 7 & 4 & 1 & 1 & $0.5775 \pm 0.0805$ & $0.005359 \pm 0.004360$ \\
\hline
\end{tabular}

gat Sea (4 samples), Ligurian Sea (2 samples), and Skagerrak Sea (3 samples). In all cases, almost all of the genetic variance was within samples, and all comparisons between sampling replicates displayed negative $\Phi_{s t}$ values. Therefore, samples collected at the same site in consecutive years were considered part of the same gene pool and grouped. Moreover, AMOVAs performed on NW Atlantic populations (4 samples) did not reveal differences, thus, in this case the samples were also pooled. On the basis of these results, the AMOVA was performed on a new dataset composed of 13 populations, Alboran Sea, NW Atlantic, Azores Islands, Cadiz Bay, Clyde Sea, Greenland, Gullmarn Fijord, Kattegat Sea, Ligurian Sea, Norwegian Sea, Rockall Trough, Skagerrak Sea, and NW Spain.

The $\Phi_{s t}$ value for the 13 populations considered all together showed that the hypothesis of panmixia should be rejected with high statistical significance ( $p<0.00001)$, since a substantial percentage $(11.82 \%)$ of genetic variation depends on population subdivision (Table 3A). On the basis of this evidence we used AMOVAs in order to identify different gene pools among the investigated populations. For this purpose populations were grouped on the basis of the pairwise population compar-

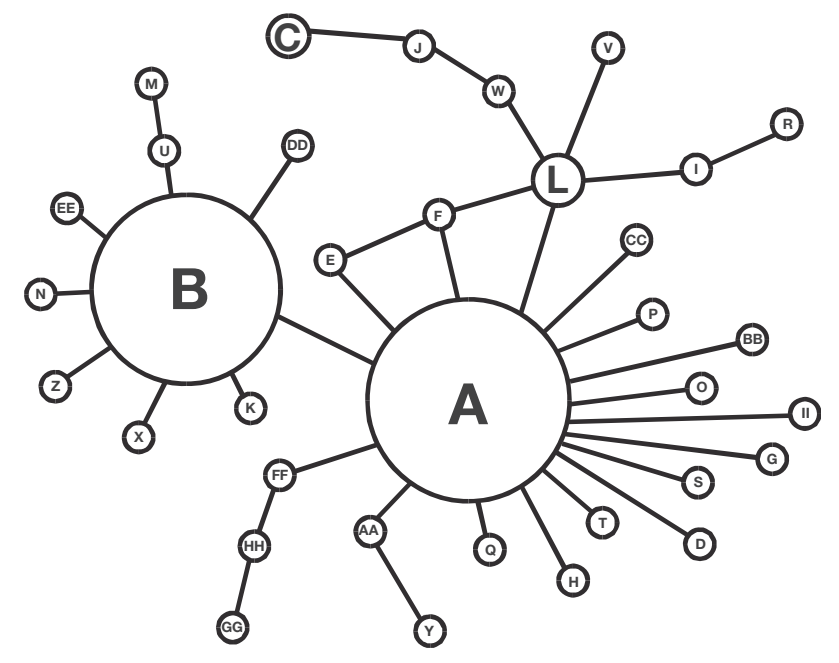

Fig. 2. Meganyctiphanes norvegica. Network representing molecular relationships between haplotypes of the $M$. norvegica ND1 mitochondrial sequence. Most frequent haplotypes $(\mathrm{A}, \mathrm{B}, \mathrm{L}, \mathrm{C})$ were represented by circles whose size is proportional to their frequency. Haplotypes with frequency below $1 \%$ are not drawn to scale 
Table 3. AMOVA analysis of Meganyctiphanes norvegica. Fixation index ( $\Phi$ statistics) are reported for different groupings (A, B, C, D, E). The probability of obtaining a higher $\Phi$ value by chance is also indicated (as estimated by 10000 permutations)

\begin{tabular}{|c|c|c|}
\hline Dataset & F-statistic & $\mathrm{p}$ \\
\hline A 13 populations in 1 group & $\Phi_{s t}=0.11824$ & $<0.00001$ \\
\hline $\begin{array}{l}\text { B } 13 \text { populations in } 3 \text { groups ('southern' } \\
\text { NE Atlantic Ocean, Ligurian Sea, } \\
\text { 'northern' NE Atlantic Ocean + NW } \\
\text { Atlantic Ocean + Alboran Sea) }\end{array}$ & $\begin{array}{l}\Phi_{s t}=0.21945 \\
\Phi_{s c}=0.00972 \\
\Phi_{c t}=0.21179\end{array}$ & $\begin{array}{r}<0.00001 \\
0.01524 \\
0.00172\end{array}$ \\
\hline $\begin{array}{l}\text { C } 9 \text { populations in } 1 \text { group ('northern' } \\
\text { NE Atlantic Ocean + NW Atlantic } \\
\text { Ocean + Alboran Sea) }\end{array}$ & $\Phi_{s t}=0.00866$ & 0.03817 \\
\hline $\begin{array}{l}\text { D } 9 \text { populations in } 2 \text { groups ('northern' } \\
\text { NE Atlantic Ocean + NW Atlantic } \\
\text { Ocean + Alboran Sea) }\end{array}$ & $\begin{array}{l}\Phi_{s t}=0.01430 \\
\Phi_{s c}=0.00773 \\
\Phi_{c t}=0.00662\end{array}$ & $\begin{array}{l}0.03830 \\
0.19636 \\
0.22170\end{array}$ \\
\hline $\begin{array}{l}\text { E } 9 \text { populations in } 2 \text { groups (NW Atlantic } \\
\text { Ocean, 'northern' NE Atlantic Ocean + } \\
\text { Alboran Sea) }\end{array}$ & $\begin{array}{l}\Phi_{s t}=0.04390 \\
\Phi_{\text {sc }}=0.00434 \\
\Phi_{c t}=0.03974\end{array}$ & $\begin{array}{r}0.03859 \\
0.14808 \\
<0.00001\end{array}$ \\
\hline
\end{tabular}

ved only between NW Atlantic and Alboran, Ligurian, Clyde and Norwegian samples; (2) positive $\Phi_{\text {st }}$ values also resulted between several samples belonging to the 'northern' NE Atlantic region (i.e. Clyde vs. Greenland, $\Phi_{s t}=$ 0.032), whereas temporal replicates within the same sites showed negative $\Phi_{\text {st }}$ value. These 2 observations show that there is an appreciable degree of divergence of the NW Atlantic sample, and a large genetic homogeneity of the temporal replicates.

In order to provide a graphical representation of relationships among the investigated samples, we used the pairwise AMOVA matrix to generate a dendrogram using the UPGMA algorithm (Nei \& Kumar 2000). The tree (Fig. 3) clearly supports the distinction of 3 major gene pools, the most di-

isons (Table 4). In fact, pairwise $\Phi_{\text {st }}$ pointed out those samples deviating from panmixia; in particular the samples from Azores Island, Cadiz Bay, NW Spain and the Ligurian populations appeared to be the most divergent, as the majority of the $\Phi_{s t}$ values from these population displayed significant values (Table 4). Accordingly, we subdivided the 13 populations into 3 groups, the 'southern' NE Atlantic (which includes Azores Island, Cadiz Bay and NW Spain), the Ligurian one, and a third group including the 9 remaining populations that were collected in the 'northern' NE Atlantic Ocean, in the NW Atlantic Ocean and in the Alboran Sea (see Table 1). The AMOVA analysis showed a very high $\Phi_{c t}$ value indicating that a large part (about $21 \%$ ) of the genetic variability is due to subdivision between groups (Table 3B). However, further substructure among the 9 populations collected in the 'northern' NE Atlantic Ocean, the NW Atlantic Ocean and the Alboran Sea is evident by the $\Phi_{s t}$ value shown in Table $3 \mathrm{C}$. When different subdivisions of this group of 9 populations were tested, the one that maximized the $\Phi_{c t}$ value was the separation of the NW Atlantic population from the 'northern' NE Atlantic (Clyde Sea, Greenland, Gullmarn Fijord, Kattegat Sea, Norwegian Sea, Rockall Trough, Skagerrak Sea ) + the Alboran Sea populations (Table 3E).

Interestingly, the Alboran Sea population (collected in Mediterranean waters, but geographically very close to the Cadiz Bay sample) (Fig. 1) appeared genetically closer to the 'northern' NE Atlantic populations. Two other trends are evident upon examination of the $\Phi_{\text {st }}$ pairwise matrix of Table 4: (1) NW Atlantic samples showed $\Phi_{s t}$ positive values in all comparisons, and were often associated with significant or marginally significant p-values; weak differentiation was obser- vergent of which appears to be the 'southern' NE Atlantic group (Azores Islands + Cadiz Bay + NW Spain). Considering the other 2 major branches of the dendrogram, the grouping of Ligurian and NW Atlantic populations was quite unexpected. This result might be due to the presence of a few individuals carrying Haplotype $\mathrm{C}$ in both populations. Haplotype $\mathrm{C}$ was highly divergent (separated by 4 and 5 mutational steps) from the most frequent haplotypes, A and B, respectively (Fig. 2). Considering the limited length of the sequence analysed, we cannot exclude that the Haplotype $\mathrm{C}$ shared by the 2 populations contains homoplasic information. To test this hypothesis, we compared the 13 populations using only Haplotypes A and $\mathrm{B}$, pooling all others into a single category of rare haplotypes. In this case, the sequence information was not considered, and the $F_{s t}$ is based on frequency information only. The pairwise matrix obtained from the conventional $F_{\text {st }}$ (not shown) was then used to generate a new UPGMA dendrogram (Fig. 4). This new tree showed 4 major groups: (1) the highly divergent 'southern' NE Atlantic populations (with some degree of differentiation among the 3 samples); (2) the 'northern' NE Atlantic group, with all populations collected in this area being very closely related; (3) the NW Atlantic samples which were placed in this new tree as sister taxa to the 'northern' NE Atlantic populations, but clearly distinct from them (although the Alboran Sea sample appeared associated to the NW Atlantic one); and (4) the Ligurian population, which was placed in a well-separated branch of the tree.

We estimated the divergence time between the 3 Atlantic pools according to Gaggiotti \& Excoffier (2000) assuming an average mutation rate of 0.88 to 


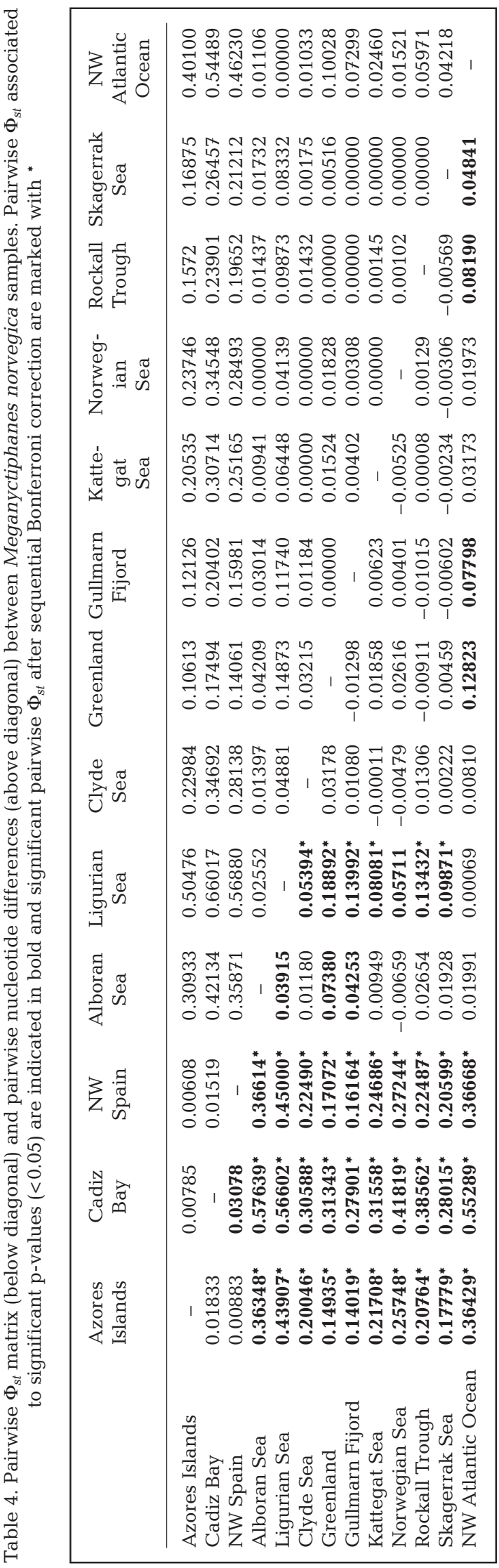

$1.3 \times 10^{-8}$ per site per year and a generation time of $1 \mathrm{yr}$ (Zane et al. 2000 and references therein). The Ligurian sample was not included in this analysis because of the genetic convergence with the NW sample. The results showed that the 2 most divergent groups ('southern' NE Atlantic and NW Atlantic) have been separated for a period ranging between 9.0 and 14.0 million $\mathrm{yr}$, whereas the 'northern' NE Atlantic and NW Atlantic groups were separated most recently (0.6 to 1.0 million yr ago).

\section{DISCUSSION}

Genetic differentiation among populations of Meganyctiphanes norvegica was documented by previous investigations (Bucklin et al. 1997, Zane et al. 2000). The present study was aimed at providing a more detailed picture of the genetic variability and differentiation among populations across almost the entire natural distribution area of the species. This was achieved by extending the dataset presented in Zane et al. (2000) both temporally and geographically.

Many studies have been carried out on marine species, but they have rarely assessed temporal stability of the intra-specific genetic structure. This work indicates that there is genetic homogeneity among temporal replicates (for up to 4 consecutive yr) in the Kattegat Sea (1995-1998), Clyde Sea (1997, 1998), Skagerrak Sea (1996-1998), and Ligurian Sea (1996, 1997). This finding is interesting if we consider that krill are planktonic organisms, supposedly subject to passive transport, which should prevent the formation of genetically isolated populations (Zane \& Patarnello 2000). Evidence of restricted gene flow in Meganyctiphanes norvegica clearly emerged from this work. This result is in line with previous studies (Bucklin et al. 1997, Zane et al. 2000), although genetic homogeneity among populations of this species has also been reported (Sundt \& Fevolden 1996). The latter observation, however, regarded samples that were collected within a limited geographic range of the NE sector of the Atlantic Ocean, which might indeed belong to an homogeneous gene pool.

The present work covered a greater part of the natural distribution of the species, allowing a better definition of the northern krill's genetic structure. The AMOVA analysis significantly rejected the hypothesis of panmixia identifying differentiated gene pools that could be roughly separated into 3 major groups. Two of these are on the eastern side of the North Atlantic and are referred as 'northern' NE Atlantic (above $55^{\circ} \mathrm{N}$ ) and 'southern' NE Atlantic (below $45^{\circ} \mathrm{N}$ ). The third group was found in the Ligurian Sea and possibly represents a distinct Mediterranean gene pool. Such 


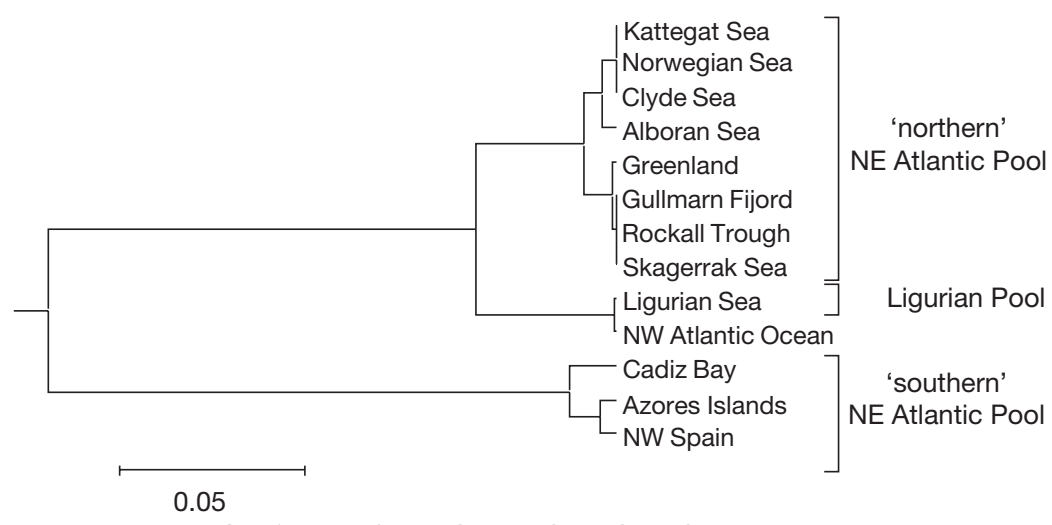

Fig. 3. UPGMA tree of populations based on the $\Phi_{\text {st }}$ pairwise matrix

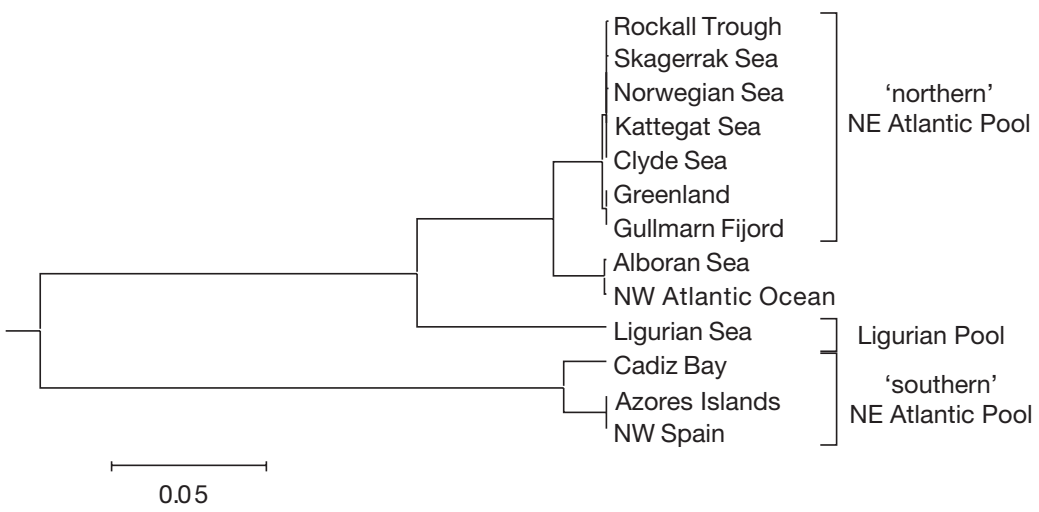

Fig. 4. UPGMA tree of populations based on the conventional $F_{\text {st }}$ pairwise matrix, reconstructed considering the frequency information of 3 haplotype categories only (A, B and 'pooled rare haplotypes')

genetic structure has been suggested by previous investigations (Zane et al. 2000), and is further supported by the extended sample set presented in this study.

The existence of a 'southern' NE Atlantic population was initially proposed on the basis of the result obtained for the Cadiz Bay population (Zane at al. 2000). The addition of 2 new samples, from the Azores Islands and NW Spain, apparently belonging to the same gene pool, strongly supports this view. The high divergence of the 'southern' NE Atlantic populations was confirmed in the present analysis, although the origin of this southern gene pool is still unclear. In this regard, the possible occurrence of a source population off the Morocco coast was hypothesized, which could be advected by ocean currents flowing northward at depths of 200 to $400 \mathrm{~m}$ (Thiriot 1997, Zane et al. 2000). Our findings also confirmed the genetic separation of the Ligurian population, which has been supported by independent ecological and physiological observations (Cuzin-Roudy 2000). A large gene pool, homogeneous over time and space, appears to be composed of the 'northern' NE Atlantic populations, to which the Gullmarn Fijord, Greenland and Norwegian samples were added as new locations in this work. Only in 1 case did we observe differences within 'northern' NE Atlantic populations (i.e. Greenland vs. Clyde Sea), however this difference was not significant after sequential Bonferroni correction ( $\mathrm{p}=$ 0.038). The 'northern' NE Atlantic samples probably belong to a stable breeding unit with high levels of gene flow, possibly promoted by the oceanographic features of the area, where mixing of water masses favours an extensive larval exchange, thus preventing population differentiation (Bowden 1975, Zane et al. 2000).

An earlier study, carried out on Meganyctiphanes norvegica samples collected from the NW Atlantic and from a Norwegian fjord, revealed no major differences within NW Atlantic populations; there was however a significant degree of separation between them and the Norwegian sample (Bucklin et al. 1997), suggesting the possibility of restricted gene flow between the NW and NE Atlantic provinces. We analysed some of the samples from Bucklin et al. (1997) in order to test whether the NW Atlantic populations constitute a separate breeding unit. The sequence analysed (the ND1 fragment), showed an unexpected convergence of the NW Atlantic samples with the Ligurian population. This was particularly evident in the UPGMA tree obtained from the $\Phi_{s t}$ pairwise matrix. A possible explanation for the apparent close affinity between the 2 samples is the limited length of the investigated sequence which might also contain homoplasic information. In particular, the presence in both groups of several individuals displaying Haplotype $\mathrm{C}$ might be in large part responsible for the closeness of the NW Atlantic and Ligurian samples; especially because Haplotype $\mathrm{C}$ is one of the most divergent types, with several mutational steps separating it from the 2 most frequent haplotypes, A and B (Fig. 2). The presence of aberrant mitochondrial haplotypes has been noted previously for marine organisms. Bucklin \& Kocher (1996) suggested that such haplotypes may be explained by under-sampling of the genetic diversity of extremely numerous organisms or by sampling patches of organisms transported from distant regions. We therefore decided to base the genetic comparisons among populations only on the 
frequency distribution of Haplotypes A and B, pooling all the others in a single category of 'rare haplotypes'. We generated a conventional $F_{s t}$ matrix (thus not considering sequence information) with which we produced a new UPGMA tree (Fig. 4) which showed differences not revealed by the $\Phi_{s t}$ matrix. This tree showed a more convincing grouping, with the NW Atlantic samples placed as sister taxa to the 'northern' NE Atlantic gene pool, though clearly separated from it. The Alboran Sea population appeared more closely related to the NW Atlantic sample than to the Ligurian one, the latter is clearly a distinct population. The hydrographic and ecological features of the Alboran Sea are indeed more similar to the Atlantic Ocean than to the Mediterranean Sea (Estrada et al. 1985, Kiortsis 1985), thus, it is not surprising that the population collected in this area clusters with Atlantic samples. It was suggested that the transitional area between Atlantic and Mediterranean conditions is associated with the Oran-Almeria front, eastward to the Strait of Gibraltar (Bargelloni et al. 2003). A pronounced step change in microsatellite allele frequencies was in fact reported for the cephalopod Sepia officinalis in association with the Oran-Almeria front (Perez-Losada et al. 2002). It is however difficult to establish whether the Alboran population belongs to the 'northern' NE Atlantic or to the NW Atlantic pool as alternatively suggested by the tree topology of Figs. 3 and 4 respectively; although the first option appears more reasonable. Unexpected is the large genetic divergence between the Alboran and the Cadiz Bay samples given their geographic proximity. A more appropriate sampling in that area may provide more insight. The 'southern' NE Atlantic and 'northern' NE Atlantic populations were confirmed to be distinct gene pools using the conventional $F_{s t}$. The Norwegian population appeared well-placed within the NE Atlantic group; this was expected considering its geographic position and is also in keeping with earlier work by Bucklin et al. (1997) who identified the Norwegian pool as distinct from the NW Atlantic one.

In conclusion, the present data provide consistent evidence of the presence of at least 3 distinct gene pools across the North Atlantic Ocean, which are geographically separated and located in the NW, 'northern' NE and 'southern' NE Atlantic sectors. These genetically distinct groups appear to correspond to ocean basin-scale patterns of circulation, which partition the North Atlantic into 3 gyres, and may effectively isolate the entrained ecosystems and populations. A 4th gene pool is clearly associated with the Ligurian samples, suggesting the existence of a separate Mediterranean population. This possibility is not surprising and seems in line with similar observations on other marine organisms for which an Atlantic/
Mediterranean separation was reported at the intraspecific level (Bargelloni et al. 2003 and references therein). The population subdivision across the North Atlantic Ocean may be explained by major ocean currents and gyres, which may represent a limitation to the gene flow and favour population structuring at such large geographic scales (see e.g. Aksnes \& Blindheim 1996, Bucklin et al. 2000). However, the northern krill present-day structure must have been established over a geological time scale since the separation between the Atlantic pools ranges from a minimum of 0.6 to a maximum of 14 million yr ago. Though these must be considered indicative estimates, they imply that the limitation to the gene flow (by barrier such as oceanic gyres) must have been effective over the last million years. Not only passive transport (dependent on marine circulation) but also active movement of individuals can help to maintain stable population differentiation on local scales. Krill seem to be able to counteract advection and stay in ecologically favourable water masses by active swimming and by exploiting different current velocities and directions at different depths (Sundt \& Fevolden 1996). The negative $\Phi_{s t}$ values observed between temporal replicates at the same sampling site seem to support this view, as it suggests an extremely high genetic stability of the populations over time. Further investigations aimed at providing a fine-scale picture of the population structure of this ecologically important krill species are currently in progress. By employing highly polymorphic molecular markers such as microsatellite DNA it should be possible to define, in more detail, the boundaries among Atlantic (and eventually Mediterranean) provinces, and possibly provide additional evidence for the relevant role of oceanic currents in shaping the population structure of marine species.

Acknowledgements. This paper was supported by the EU grant \#MAS3-CT-0013 and by an Italian PNRA grant to T.P. We are deeply indebted with F. Buchholz and S. Brohl (Biologische Anstalt Helgoland, BAH, Germany), P. Mayzaud and J. Cuzin-Roudy (Observatoire Océanologique, Villefranche/ mer, France), G. Tarling (SAM, Oban, Scotland, presently at the British Antarcit Survey), who kindly provided us with samples. Warm acknowledgments are due P. H. Wiebe (Woods Hole Oceanographic Institution) for critical advice on manuscript preparation, as well as J. G. Beaudet and S. B. Smolenack (both University of New Hampshire) for technical assistance. Support for A.B. was provided by the US NSF Biological Oceanography Program (No. OCE-0003884).

\section{LITERATURE CITED}

Aksnes DL, Blindheim J (1996) Circulation patterns in the North Atlantic and possible impact on the population of Calanus finmarchicus. Ophelia 44:7-28

Bandelt HJ, Forster P, Sykes BC, Richards MB (1995) Mitho- 
condrial portraits of humans populations using median networks. Genetics 141:743-753

Bargelloni L, Alarcon JA, Alvarez MC, Penzo E, Magoulas A, Reis C, Patarnello T (2003) Discord in the family Sparidae (Teleostei): divergent phylogeographical patterns across the Atlantic-Mediterranean divide. J Evol Biol 16: $1149-1158$

Bérubé M, Aguilar A, Dendanto D, Larsen F and 5 others (1998) Population genetic structure of North Atlantic, Mediterranean and Sea of Cortez finwhales, Balaenoptera physalus (Linnaeus 1758): analysis of mitochondrial and nuclear loci. Mol Ecol 15:585-599

Boucher J, Thiriot A (1972) Zooplancton et micronecton estivaux des deux cents premiers metres en Meditérranée Occidentale. Mar Biol 15:47-56

Bowden KF (1975) Oceanic and estuarine mixing processes. In: Riley JP, Skirrow G (eds) Chemical oceanography, Vol 1. Academy Press, New York, p 1-41

Buchholz F, Boysen-Ennen E (1988) Meganyctiphanes norvegica in the Kattegat: studies on the horizontal distribution in relation to hydrography and zooplankton. Ophelia 29:71-82

Buchholz F, David P, Matthews J, Mayzaud P, Patarnello T (1998) Impact of climatic gradient on the physiological ecology of a pelagic crustacean (PEP). Proc 3rd Eur Mar Sci Tech Conf, Vol 1: Marine Systems, p 39-48

Bucklin A, Kocher TD (1996) Source regions for recruitment of Calanus finmarchicus to Georges Bank: evidence from molecular population genetic analysis of mtDNA. DeepSea Res 43:1665-1682

Bucklin A, Smolenack SB, Bentley AM, Wiebe PH (1997) Gene flow patterns of the euphausiid, Meganyctiphanes norvegica, in the N Atlantic based on DNA sequences for mitochondrial cytochrome oxidase I and cytochrome b. J Plankton Res 19:1763-1781

Bucklin A, Wiebe PH, Astthorsson OS, Gislason A, Allen LD, Smolenack SB (2000) Population genetic variation of Calanus finmarchicus in Icelandic waters: preliminary evidence of genetic differences between Atlantic and Polar populations. ICES J Mar Res 57:1592-1604

Clement M, Posada D, Crandall KA (2000) TCS: a computer program to estimate gene genealogies. Mol Ecol 9:1657-1660

Cockerham CC (1969) Variance of gene frequencies. Evolution 23:72-83

Cockerham CC (1973) Analyses of gene frequencies. Genetics 74:679-700

Cuzin-Roudy J (2000) Seasonal reproduction, multiple spawning, and fecundity in northern krill, Meganyctiphanes norvegica, and Antarctic krill, Euphausia superba. Can J Fish Aquat Sci 57:6-15

Estrada M, Vives F, Alcaraz M (1985) Life and productivity of the open sea. In: Margalef R (ed) Western Mediterranean. Pergamon Press, Oxford, p 148-197

Excoffier L, Smouse P, Quattro JM (1992) Analysis of molecular variance inferred from metric distances among DNA haplotypes: application to human mitochondrial DNA restriction data. Genetics 131:479-491

Forcada J, Aguilar A, Hammond P, Pastor X, Aguilar R (1993) Distribution and abundance of fin whales in the Western Mediterranean Sea during the summer. In: Evans PGH (ed) European research on cetaceans, Vol 7. Proc XVII Ann Conf ECS, Inverness, Scotland. ECS, Cambridge p 128-131

Gaggiotti OE, Excoffier L (2000) A simple method of removing the effect of a bottleneck and unequal population sizes on pairwise genetic distances. Proc R Soc Lond B 267: 81-87
Hardy AC, Gunther ER (1935) The plankton of the South Georgia Whaling grounds and adjacent waters 1926-27. Discov Rep 11:1-456

Herman AW, Sameoto DD, Shunnian C, Mitchell MR, Petrie B, Cochrane N (1991) Sources of zooplankton on the Nova Scotia shelf and their aggregations within deep shelf basins. Cont Shelf Res 11:211-238

Hudson RH (1990) Gene genealogies and the coalescent process. In: Futuyama D, Antonovics J (eds) Oxford surveys in evolutionary biology, Vol 7. Oxford University Press, Oxford, p 1-44

Kils U (1982) The swimming behavior, swimming performance and energy balance of Antarctic krill Euphausia superba. BIOMASS Scientific Series 3:1-121

Kiortsis V (1985) Mediterranean marine ecosystems: establishment of zooplanktonic communities in transitional and partly isolated areas. In: Moroitou-Apostolopoulou M, Kiortsis V (eds) Mediterranean marine ecosystems. NATO Conference Series I, Ecology 8. Plenum Press, New York, p 377-385

Lindley JA (1982) Population dynamics and production of Euphausiids III. Meganyctiphanes norvegica and Nyctiphanes couchii in the North Atlantic Ocean and the North Sea. Mar Biol 66:37-46

Mauchline J (1980) The biology of mysids and euphausiids Part 2. The biology of euphausiids. Adv Mar Biol 18:1-681

Mauchline J, Fisher LR (1969) The biology of euphausiids. Adv Mar Biol 7:1-454

Nei M, Kumar S (2000) Molecular Evolution and Phylogenetics. Oxford University Press, New York

Nei M, Miller SC (1990) A simple method for estimating average number of nucleotide substitutions within and between populations from restriction data. Genetics 125: 873-879

Ostellari L, Bargelloni L, Penzo E, Patarnello P, Patarnello T (1996) Optimization of single-strand conformation polymorphism and sequence analysis of the mitochondrial control region in Pagellus bogaraveo (Sparidae, Teleostei): rationalized tools in fish population biology. Anim Genet 2:423-427

Perez-Losada M, Guerra A, Carvalho GR, Sanjuan A, Shaw PW (2002) Extensive population subdivision of the cuttlefish Sepia officinalis (Mollusca: Cephalopoda) around the Iberian Peninsula indicated by microsatellite DNA variation. Heredity 89:417-424

Rice RW (1989) Analyzing tables of statistical tests. Evolution 43:223-225

Saborowski R, Brohl S, Tarling GA, Buchholz F (2002) Metabolic properties of Northern krill, Meganyctiphanes norvegica, from different climatic zones. I. Respiration and excretion. Mar Biol 140:547-556

Schneider S, Roessli L, Excoffier L (2000) Arlequin 2.000: a software for population genetics data analysis. University of Geneva. Available at: http://anthro.unige.ch/arlequin

Siegel V (2000) Krill (Euphausiacea) demography and variability in abundance and distribution. Can J Fish Aquat Sci 57:151-167

Sundt RC, Fevolden SE (1996) Homogeneous genetic structure of Meganyctiphanes norvegica (Euphausiacea) in the north-east Atlantic Ocean, as interpreted from allozymic variation. Sarsia 81:155-159

Taki K, Kotani Y, Kuroda K, Kasuya T (1993) Effect of surface water temperature and salinity on the catch of Euphausia pacifica in the near shore water off the Onagawa coast, Miyagi Pretecture, northern Japan. Bull Tohoku Nat Fish Inst 55:29-35

Tarling G, Buchholz F, Matthews J (1999) The effect of lunar eclipse on the vertical migration behaviour of Meganyc- 
tiphanes norvegica (Crustacea: Euphausiacea) in the Ligurian Sea. J Plankton Res 21:1475-1488

Tarling GA, Matthews JBL, David P, Guerin O, Buchholz F (2001) The swarms dynamics of northern krill (Meganyctiphanes norvegica) and pteropods (Cavolinia inflexa) during vertical migration in the Ligurian Sea observed by acoustic Doppler current profiler. Deep-Sea Res 48: 1671-1686

Thiriot A (1997) Peuplements zooplanctoniques dans les regions de remontees d'eau du littoral Atlantique africain. Doc Sci Cent Rech Oceanogr Abidjan 8:1-72

Walsh PS, Metzger DA, Higuchi R (1991) Chelex 100 as a medium for simple extraction of DNA for PCR based typing from forensic material. Biotechniques 10:506-513

Worthington EB (1931) Vertical movements of freshwater

Editorial responsibility: Simon Archer (Contributing Editor), Guildford, UK macroplankton. Int Rev Gesamten Hydrobiol Hydrogr 25: 394-436

Zane L, Ostellari L, Maccatrozzo L, Bargelloni L, Battaglia B, Patarnello T (1998) Molecular evidence for genetic subdivision of Antarctic krill (Euphausia superba Dana) populations. Proc R Soc Lond B 265(1413):2387-2391

Zane L, Ostellari L, Maccatrozzo L, Bargelloni L, CuzinRoudy J, Buchholz F, Patarnello T (2000) Genetic differentiation in a pelagic crustacean (Meganyctiphanes norvegica Euphausiacea) from the North east Atlantic and the Mediterranean Sea. Mar Biol 136:191-199

Zane L, Patarnello T (2000) Krill: a possible model for investigating the effects of ocean currents on the genetic structure of a pelagic invertebrate. Can J Fish Aquat Sci $57: 1-8$

Submitted: August 19, 2004; Accepted: December 17, 2004 Proofs received from author(s): March 8, 2005 